\title{
ENSINO E APRENDIZAGEM DE HABILIDADES AFETIVAS DO PROFISSIONAL DA ÁREA DA SAÚDE
}

\author{
Edna Amari Shiratsu Takahashi ${ }^{1}$, Maria Eliza Nigro Jorge ${ }^{2}$ \\ ${ }^{1}$ Farmácia, Medicina - UNOESTE. ${ }^{2}$ Núcleo de Educação à Distância - UNOESTE. E-mail: edna@unoeste.br
}

\section{RESUMO}

O presente artigo utilizou a metodologia da pesquisa bibliográfica em bancos de dados eletrônicos e livros referenciais para contextualizar a formação generalista do profissional da área da saúde, a transposição do modelo flexneriano para o modelo interacionista. As novas orientações trazem foco na atenção básica, envolvem medidas preventivas ao processo saúde-doença e utilizam como ferramenta de trabalho as relações interpessoais. Abordaram-se os objetivos educacionais, segundo a Taxionomia de Bloom, para demonstrar a integralidade da educação. Foi explorado o ensino e a aprendizagem do domínio afetivo, sua relevância no sistema educacional na formação de pessoas com capacidade de utilizar conhecimentos para transformar a sua realidade de modo favorável, tanto quanto a sua realização profissional e pessoal. As habilidades afetivas podem ser ensinadas e aprendidas, mas representam um desafio teórico e metodológico suas técnicas de avaliação na promoção de mudanças internalizadas.

Palavras-chave: Ensino. Aprendizagem. Habilidades afetivas. Saúde.

\section{INTRODUÇÃO E OBJETIVO}

As universidades assumem grande responsabilidade de transmitir o saber, desenvolver a capacidade intelectual e sócio-afetiva na formação integral do aluno para gerar profissionais com personalidade social, cultural e ética. No Brasil e em vários países, questiona-se a real função do sistema educacional, principalmente das universidades. O mundo globalizado e a grande velocidade de informações e mudanças não permitem uma abordagem curricular pautada em volume de conteúdos, nem sempre refletindo uso operacional e adequado dos mesmos. A qualidade representa mais competitividade e modernização das organizações (AGUILAR-da-SILVA et al.,2009; MARCHESAN; SOUZA; MENEZES, 2011).

Entre as décadas de 1980 e 1990 as instituições de ensino superior receberam críticas, divulgadas nos meios de comunicações. Algumas áreas para a formação do profissional da saúde estavam em desarticulação entre a teoria e a prática, o processo saúde e doença, além do modelo de uso do hospital universitário como centro de atividades práticas, com ênfase nas especialidades, não privilegiando o indivíduo como um ser integral. Frente às necessidades por qualidade e melhorias na gestão universitária, iniciou-se o uso do termo "avaliação institucional" (STELLA et al., 2009). Deste modo, na década de 1990, a Associação Brasileira de Educação Médica foi uma das pioneiras ao coordenar o movimento de avaliação das escolas médicas. Este 
movimento culminou na formulação das Diretrizes Curriculares Nacionais (DCN), instituídas em 2001 para os cursos da área da saúde (LAMPERT et al., 2009).

As DCN objetivam, por meio do sistema educacional, a formação de pessoas na sociedade com capacidade de utilizar seus conhecimentos para transformar a sua realidade de modo favorável. Anteriormente às decisões das DCN, a formação dos profissionais da área da saúde era centrada no modelo flexneriano, em especialidades médicas, nas habilidades cognitivas e psicomotoras, relevando o conteúdo humanístico e a promoção da saúde. As novas orientações trazem foco na atenção básica, que envolvam medidas preventivas ao processo saúde-doença e utilizem como ferramenta de trabalho as relações interpessoais (LAMPERT et al., 2009; STELLA et al., 2009).

Com a iniciativa governamental, para apoiar a implementação das DCN de graduação em Medicina, criou-se o Programa Nacional de Reorientação da Formação Profissional em Saúde (PróSaúde). Na mesma época o Ministério da Saúde, em parceria com o Instituto de Estudos e Pesquisa Educativas Anísio Teixeira e docentes e pesquisadores de diferentes regiões do país, estudaram a adesão dos cursos de graduação de Enfermagem e Odontologia às DCN, instituídos a estes cursos em 2001 e 2002 respectivamente. Em decorrência disso, em 2006, ampliou-se à PróSaúde I com a inserção dos cursos de Enfermagem e Odontologia. Estes três profissionais eram contemplados na Estratégia de Saúde da Família. O movimento para a inserção de outros profissionais da saúde na atenção básica no Sistema Único de Saúde (SUS), associada à recomendação do Conselho Nacional de Saúde, estendeu-se em 2007 à Pró-Saúde II. A abrangência do Pró-Saúde II, para as quatorze profissões integrantes da área da saúde, fortaleceu a efetiva implementação das DCN e na reorientação da formação profissional (HADDAD et al., 2012).

Condizente com a responsabilidade das universidades na educação contemporânea espera-se que a conduta na prática, dos profissionais da área da saúde, apresente atitudes positivas para com o paciente. Neste contexto as atitudes assumem grande relevância, pois são os comportamentos que determinam como os indivíduos se posicionam frente aos outros e aos acontecimentos. Entretanto, observa-se uma crescente desvalorização humanística, perda crescente do idealismo e empatia, aumento do ceticismo, perda dos sentimentos de realização e satisfação com a escolha profissional (ANDRADE et al., 2011). Realidade que vai ao desencontro com os objetivos das DCN de formação de profissional socialmente habilidoso da área da saúde, 
na "busca de resolver uma situação ao mesmo tempo em que minimiza a probabilidade de problemas futuros" (DEL PRETTE et al., 1998).

Segundo Miranda et al. (2009) a atitude, considerada parte importante das habilidades afetivas, pode ser ensinada e aprendida. Deste modo, faz-se necessário o desenvolvimento de habilidades sociais, tais como fazer e responder perguntas, escutar empaticamente, trabalhar em equipes e entre outros para o êxito profissional (ANDRADE et al., 2011; DEL PRETTE et al., 1998).

O objetivo deste trabalho foi contextualizar o ensino e aprendizagem da habilidade afetiva associadas com as habilidades cognitivas e psicomotoras na formação do profissional da área da saúde.

\section{METODOLOGIA}

A metodologia empregada foi de pesquisa bibliográfica em base de dados eletrônicos Scielo, com as palavras descritoras "técnicas e instrumentos de avaliação", "avaliação em saúde", "atitude". A contextualização se baseou em leitura de artigos científicos em língua portuguesa, livros de referência bibliográfica usuais ao assunto, análises e comparações.

\section{RESULTADOS}

A leitura de Taxionomia de objetivos educacionais: 1 domínio cognitivo (BLOOM et al., 1977), já na 6a edição, foi intrigante para a iniciação dos aspectos pedagógicos da avaliação do ensino-aprendizagem. A intenção foi classificar de forma criteriosa (por isso taxionomia, e não uma decisão arbitrária) a ação de comportamentos pretendidos com a educação. Comportamentos que, desde que o mundo é mundo, as civilizações se preocupam com o futuro de seus filhos, em indagações tais como: quais serão as suas necessidades? e seus interesses?, qual seu nível atual de desenvolvimento?, quais os problemas que provavelmente encontrarão?, quais oportunidades poderão ter para trabalhar e auto-realizar-se?, quais as novas exigências? As relações humanas, na qualidade de um ser racional, utilizam dentre outros aspectos, as experiências vividas como meio de perpetuar sua existência. A necessidade de ordenação destas crenças e experiências está na essência do processo educacional, a dinâmica do ensino e aprendizagem.

De acordo com Bloom et al. (1977) o processo de formação de um indivíduo engloba o ensino-aprendizagem em várias esferas como a escola, família, sociedade, ambiente sociocultural, etc. Na formulação da Taxionomia de Objetivos Educacionais: 1 domínio cognitivo, observou-se 
que o objetivo mais comum na educação norte-americana era (e ainda o é em nosso meio) a aquisição de conhecimento ou informação. O conhecimento é um importante objetivo ou resultado da aprendizagem. Mas o que é conhecido para um grupo pode não ser conhecido ou necessário para outro grupo. Apresenta-se, no entanto, como justificativa que a aquisição de conhecimento pode determinar um acréscimo na percepção da realidade, o poder de interagir e transitar melhor com o mundo em que vive.

Ainda Bloom et al. (1977) ressalta a capacidade de empregar o conhecimento, a aplicabilidade de tal informação em situações novas e na resolutividade dos problemas. A capacidade (é a associação de habilidade + conhecimento) de solucionar esses eventos, ao se empregar técnicas adequadas, as informações necessárias e a operacionalização do processo foram chamadas de "pensamento crítico", "pensamento reflexivo" ou ainda por "solução de problemas". Baseado nos objetivos educacionais, apesar de reconhecerem que os componentes não são dissociados, estabeleceu-se os três domínios da Taxionomia de Bloom et al.: cognitivo, afetivo e psicomotor.

Segundo Bloom, Krathwohl e Masia (1976), autores da Taxionomia de objetivos educacionais: 2 domínio afetivo, foi um desafio escrever por algo tão desejado entre os educadores e ao mesmo tempo com escassez de dados e material para tal análise. Uma das inseguranças em se avaliar o ensino-aprendizagem do domínio afetivo está diretamente relacionada com o orgulho da cultura ocidental, em ferir a democracia.

A democracia acredita na educação para o livre arbítrio do indivíduo. Pode e deve a educação ajudar a ampliar sua visão de mundo, analisar seus sentimentos e medos, mas a escolha e decisão são pessoais. De forma alguma, os educadores em sua ética, querem sequer aventar que a avaliação do domínio afetivo insinue a possibilidade de doutrinação, em reduzir a autonomia do aluno. Outro ponto é a avaliação do domínio cognitivo do ensino-aprendizagem ser considerado um "jogo limpo". Existe a hesitação em fazer a avaliação do domínio afetivo pela dificuldade de se construir um instrumento de avaliação adequado, capaz de coibir os estudantes em detectar as respostas premiadas se não houver realmente a compreensão do tema proposto, quando o estudante deseja apresentar somente uma imagem socialmente aceitável (BLOOM; KRATHWOHL; MASIA, 1976; MIRANDA et al., 2009).

A dificuldade dos organizadores foi em definir claramente quais seriam os objetivos e metas afetivas a serem realizadas. Observaram em suas pesquisas a frequência de termos como "interesse", "atitude" ou "apreciação", seguido de um objeto de acordo com o foco em estudo. 
Porém, os termos eram amplos e não delimitavam a profundidade do aprendizado. Mediante a estas considerações buscou-se organizar os objetivos, de forma gradativa a demonstrar a taxionomia propriamente dita. A ordenação dos objetivos permitiu encontrar um termo que descreveria em suma o objetivo do domínio afetivo - a internalização. O processo de internalização constituiu de: acolhimento (percepção, disposição, atenção); resposta (aquiescência, disposição, satisfação); valorização (aceitação, preferências, convicção); organização (conceitualização, organização de valores); caracterização por valor (direção, caracterização). Uma vez elaborado a taxionomia, foi possível acomodar os termos afetivos comuns: interesse, apreciação, atitudes, valor, ajustamento. De forma igual, provê o necessário tanto para o desenvolvimento da conformidade quanto da não conformidade, à medida que cada papel impregna o comportamento individual (BLOOM; KRATHWOHL; MASIA, 1976).

Em favor da dinâmica do conhecimento, na década de 60, em locais de excelência, foi dado um novo redirecionamento ao conceito de saúde. O processo saúde-doença requer agora um profissional que aborde o indivíduo como um todo, um ser biopsicossocial, inserido em uma comunidade, e seus anseios com os aspectos psicológicos, financeiros e profissionais interferem em sua percepção de como cuidar de sua saúde. Do mesmo modo, existe também a preocupação se o profissional da saúde se realiza em cuidar do próximo no mais amplo aspecto, abordados dentro da perspectiva dos objetivos educacionais, quer no domínio afetivo, cognitivo e psicomotor (LAMPERT et al., 2009; MARCHESAN; SOUZA; MENEZES, 2011).

$O$ processo de ensino-aprendizagem das habilidades afetivas aponta a necessidade dos estudantes assumirem um papel ativo na sua formação. A motivação ou o desenvolvimento de interesse é uma dos principais objetivos afetivos e são procurados como meios para fins cognitivos. O diálogo é um elemento essencial, pois cabe ao professor estimular e familiarizar o aluno à reflexão da consciência da realidade, identificação de ideologias, as relações de poder e internacionalidade, considerando o ambiente sociocultural (KURCGANT; CIAMPONE; FELLI, 2001; STELLA et al., 2009).

As DCN propõem nos currículos a formação generalista (STELLA, 2009). A formação generalista é para promover a resolutividade na porta de entrada do sistema de saúde, no que se denominam como atenção primária, atenção primeira ou atenção básica (AGUILAR-da-SILVA et al., 2009). No Brasil, segundo Lampert et al. (2009), as necessidades básicas de saúde identificam-se em: demandas sanitárias (saneamento do meio, desenvolvimento nutricional, vacinação, informação em saúde); demandas epidemiológicas (vigilância, prevenção, profilaxia e tratamento); 
demandas tipicamente clínicas(prevenção e recuperação dos eventos mais freqüentes, não do mais simples).

A metodologia de problematização de situações, ou mesmo situações controladas (simulação, filmes) ou reais estimulam a zona de desenvolvimento proximal de Vygostsky, visa a apresentar o conhecimento atual do aluno, e como resolver o problema e o que deve ser aprendido. A repetição do processo permite ao aprendiz gradativas competências, segurança e resolutividade ao buscar elementos cognitivos já vistos, assegurando a adequada atividade profissional (ARCHANJO; CORREA, 2011; KURCGANT; CIAMPONE; FELLI, 2001).

\section{DISCUSSÃO}

As propostas das DCN em 2001 para a área da saúde, com formação generalista estão reenfatizando e adequando os currículos para as necessidades atuais (LAMPERT et al., 2009). Mesmo Bloom et al. (1977) já contemplavam esta visão, pois as mudanças do futuro próximo nem sempre são previsíveis, a escola deve "valorizar extraordinariamente o desenvolvimento dos modos generalizados de abordar problemas e o conhecimento aplicável a uma ampla série de situações".

O modelo de atenção à saúde brasileira requer reformulações no sentido de integrar os dois sistemas: o utilizador e o formador de recursos humanos. Projetos educacionais de escolas e universidades em que conscientizem o utilizador como parte ativa do processo de saúde e para o formador, que não pode deixar a cargo do sistema de saúde a resolução de problemas cotidianos. É necessária uma real integração do sistema de saúde e as instituições de ensino superior para não camuflar o processo de cooperação. De forma equivocada se confunde formação generalista com formação "simplista". É preciso realmente compreender o conceito, pois gera insegurança tanto para o utilizador como para o formador de recursos humanos, se confrontado com o modelo flexneriano, símbolo do uso de tecnologias por meio de equipamentos sofisticados, apesar de sua incontestável não resolutividade ao acesso à saúde. Para a formação de um profissional da área da saúde resolutivo, entre as habilidades afetivas estaria à capacidade de fazer seus pacientes aderirem a um determinado plano de ação, pedir mudanças no estilo de vida ou prosseguirem a continuidade de um tratamento. Muitas vezes a inabilidade em transmitir as informações adequadas é decorrente pela falha cognitiva do profissional, por permitir sensações de insegurança e não capturando a atenção do paciente (ANDRADE et al., 2011; SISSON, 2009). 
O método da auto-descoberta tem sido valioso para cultivar o interesse no material de aprendizagem. O aumento da curiosidade e a atividade exploratória geram impulso para $\mathrm{O}$ conhecimento e habilidade, configurando a competência (BLOOM; KRATHWOHL; MASIA, 1976). A aprendizagem crítico-reflexivo necessita da valorização sobre a realidade na qual está inserido o aprendiz, de modo que as DCN deixam explícito onde se deve dar o processo de ensinoaprendizagem, em locais da prática de assistência a saúde. Estes aprendizados indiretos, por meio do contato com a equipe de saúde e comunidade proporcionam experiências que geram padrões ou comportamentos, atitudes e valores transmitindo a forma mais duradoura de aprendizado (KURCGANT; CIAMPONE; FELLI, 2001; STELLA et al., 2009).

Atividades pedagógicas que propiciam espelhamento de si mesmo (simulação, filmes) favorecem reflexões atitudinais e um despertar para uma nova dimensão, apreendendo melhor a complexidade humana (ARCHANJO; CORREA, 2011; KURCGANT; CIAMPONE; FELLI, 2001). Esperase que estes profissionais possam prestar serviços de qualidade e não conceba educação em saúde apenas ensinar e orientar a prevenir doenças. Sabe-se que as atitudes podem ser influenciadas pelos aspectos cognitivos, motivacionais e emocionais e da necessidade de técnicas de mensuração e promoção de mudanças atitudinais (MIRANDA et al., 2009).

\section{CONCLUSÃO}

De acordo com as orientações das DCN, a comunidade acadêmica tem buscado atualizações nas práticas pedagógicas, em oficinas de capacitação de professores, para uma formação na integralidade do profissional necessário para a realidade brasileira. É uma preocupação constante estar atualizado nas políticas educacionais, principalmente por muitos professores possuírem uma formação tecnicista e não generalista.

Representa ainda um desafio teórico e metodológico as técnicas de mensuração e a promoção de mudanças atitudinais, pois ainda não existe consenso do conceito nem suas formas de investigação (ANDRADE et al., 2011). Contudo, apesar deste hiato presente, o ensinoaprendizagem do domínio afetivo consegue demonstrar como afetam positivamente o domínio cognitivo e psicomotor para a formação do indivíduo com responsabilidade social, cultural e ética.

\section{REFERÊNCIAS}

AGUILAR-da-SILVA, R. H. et al. Abordagens pedagógicas e tendências de mudanças nas escolas médicas. Revista Brasileira de Educação Médica, Rio de Janeiro, v. 33, supl. 1, p. 53-62, 2009. 
ANDRADE, S. C. et al. Avaliação do desenvolvimento de atitudes humanísticas na graduação médica. Revista Brasileira de Educação Médica, Rio de Janeiro, v. 35, n. 4, p. 517-525, out./dez. 2011.

ARCHANJO, D. R.; CORRÊA, C. L. As ciências neurológicas sob a pesquisa humanista: uma experiência pedagógica utilizando filmes. Fisioterapia e Pesquisa, São Paulo, v. 8, n. 2, p. 110-115, abr/jun. 2011. http://dx.doi.org/10.1590/S1809-29502011000200002

BLOOM, B. S.; KRATHWOHL, D. R.; MASIA, B. B. Taxionomia de objetivos educacionais: 2 domínio afetivo. 1. ed. Porto Alegre: Globo, 1976.

BLOOM, B. S. et al. Taxionomia de objetivos educacionais: 1 domínio cognitivo. 6. ed. Porto Alegre: Globo, 1977.

DEL PRETTE, A. et al. Efeitos de uma intervenção sobre a topografia das habilidades sociais de professores. Psicologia Escolar e Educacional, Campinas, v. 2, n. 1, p. 11-22, 1998.

http://dx.doi.org/10.1590/S1413-85571998000100002

HADDAD, A. E. et al. Pró-saúde e PET-saúde: a construção da política brasileira de reorientação da formação profissional em saúde. Revista Brasileira de Educação Médica, Rio de Janeiro, v. 36, n.1, supl. 1, p. 3-4, 2012.

KURCGANT, P.; CIAMPONE, M. H. T.; FELLI, V. E. A. Avaliação de desempenho docente, discente e de resultados na disciplina administração em enfermagem nas escolas de enfermagem nc 28 I. Revista da Escola de Enfermagem da USP, São Paulo, v. 35, n. 4, p. 374-380, dez. 2001.

LAMPERT, J. B. et al. Projeto de avaliação de tendências de mudanças nos cursos de graduação nas escolas médicas brasileiras. Revista Brasileira de Educação Médica, Rio de Janeiro, v. 33, supl. 1, p. 5-18, 2009.

MARCHESAN, T. M.; SOUZA, A. M.; MENEZES, R. Avaliação do processo de ensino: uma abordagem multivariada. Produção, São Paulo, v. 21, n. 2, p. 271-283, abr./jun. 2011.

http://dx.doi.org/10.1590/S0103-65132011005000018

MIRANDA, S. M. et al. Construção de uma escala para avaliar atitudes de estudantes de medicina. Revista Brasileira de Educação Médica, Rio de Janeiro, v. 33, supl. 1, p. 104-110, 2009.

SISSON, M. C. Implantação de programas e redefinição de práticas profissionais. Revista Brasileira de Educação Médica, Rio de Janeiro, v. 33, supl. 1, p. 92-103, 2009.

STELLA, R. C. R. et al. Cenários de prática e a formação médica na assistência em saúde. Revista Brasileira de Educação Médica, Rio de Janeiro, v. 33, supl. 1, p. 63-69, 2009. 